\title{
Acute chest pain 16 days after coronary artery bypass surgery: An unusual cause
}

\author{
Meike Körner, MD, Luzern, Switzerland
}

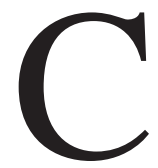

oronary artery bypass grafting $(\mathrm{CABG})$ is a widely applied procedure to treat coronary arterial disease with a relatively low complication and mortality rate. I report a case of an uncommon but serious complication.

\section{Clinical Summary}

A 54-year-old man underwent uncomplicated five-vessel CABG at my hospital. He had a history of myocardial infarction 7 years

From the Institute of Pathology, Kantonsspital Luzern, Luzern, Switzerland. Received for publication Dec 14, 2001; accepted for publication Dec 28, 2001. Address for reprints: Meike Körner, MD, Institute of Pathology, Kantonsspital Luzern, CH-6000 Luzern 16, Switzerland (E-mail meike. koerner@pathology.uhibe.ch).

J Thorac Cardiovasc Surg 2002;124:182-4

Copyright (C) 2002 by The American Association for Thoracic Surgery

$0022-5223 / 2002 \$ 35.00+0 \quad \mathbf{1 2 / 5 4} / \mathbf{1 2 2 5 3 9}$

doi:10.1067/mtc.2002.122539 before and progressive angina pectoris (New York Heart Association functional class III). Cardiovascular risk factors were arterial hypertension and cigarette smoking for years. Left ventricular ejection fraction was reduced to $45 \%$.

After discharge, on the 16th postoperative day, the patient felt a pressure in the jugular region. The intake of 2 nitroglycerin capsules yielded no relief. Approximately 12 hours later, the patient woke during night with dyspnea and a severe left thoracic and shoulder pain. He had a short episode of unconsciousness, after which the medical emergency team found a blood pressure of 90/60 $\mathrm{mm} \mathrm{Hg}$, which promptly improved to $120 / 80 \mathrm{~mm} \mathrm{Hg}$ after application of an intravenous infusion. The patient remained in stable cardiopulmonary condition during transport to the intensive care unit of the hospital. The electrocardiogram was not significantly altered from previous postoperative electrocardiograms. Chest radiography showed left ventricular enlargement and increase of the postoperative residual left pleural effusion. Serum levels of cardiac enzymes were within the reference range, whereas serum levels of fibrinogen degradation products were elevated ( $>1000 \mathrm{IU} / \mathrm{L})$. Pulmonary embolism was therefore suspected. Immediately after assessment of these data electromechan- 

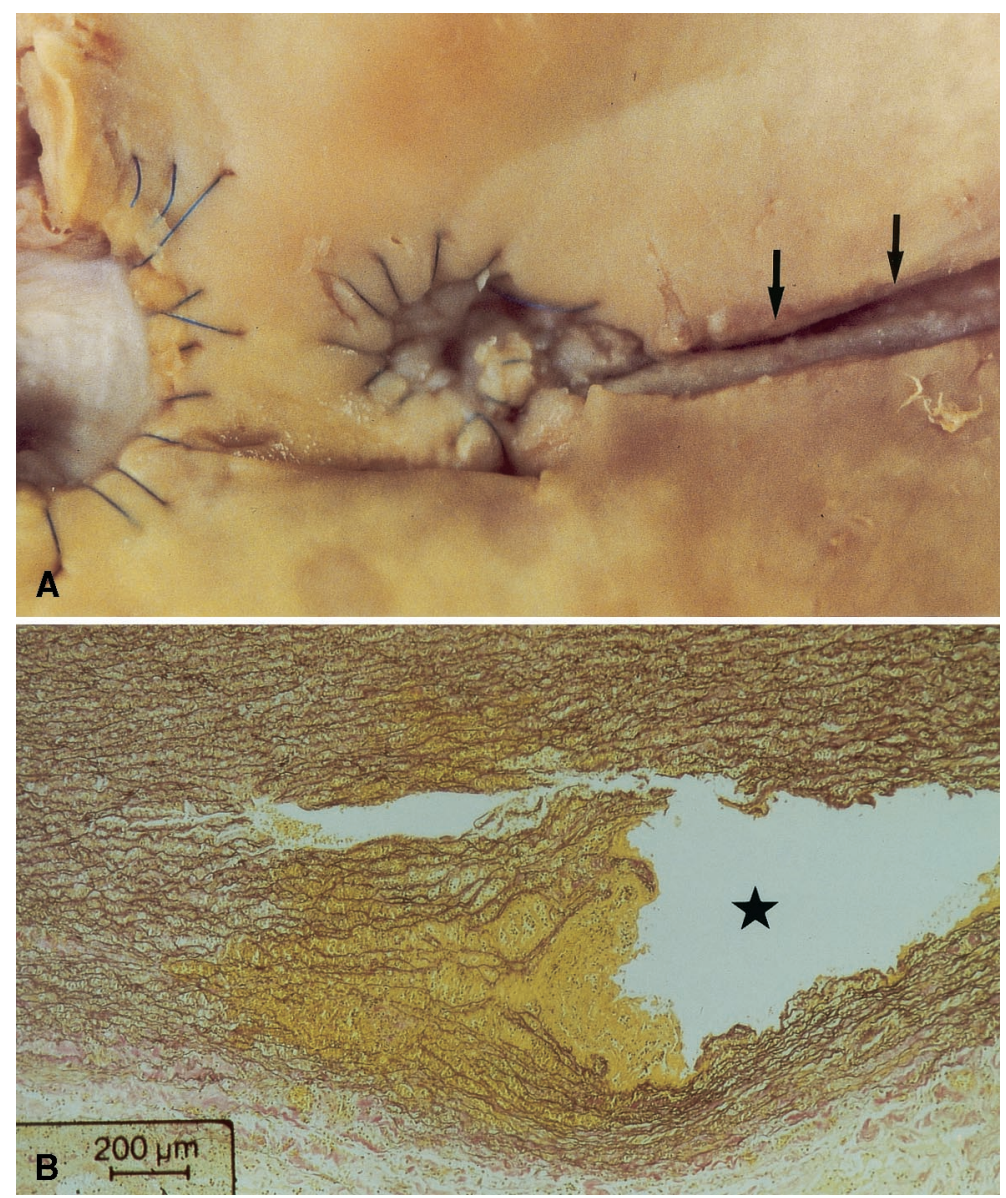

Figure 1. A, Scanning view of ascending aorta with intimal tear (arrows) continuous with coronary graft ostium 16 days after CABG. B, Histologic examination of aortic dissection with false lumen (star; elastin-van Gieson stain $\times 100)$.

ical dissociation occurred, cardiopulmonary resuscitation failed, and the patient died in asystole.

Autopsy revealed an intimal tear of the ascending aorta, including the suture line of 1 of the 2 aortocoronary venous grafts (Figure $1, A)$, an aortic dissection toward the aortic arch and aortic anulus communicating with the pericardial cavity, without compromise of the graft ostia, and cardiac tamponade with $500 \mathrm{~mL}$ blood. There was $700 \mathrm{~mL}$ of clear transudate in the left pleural cavity. All 5 coronary artery bypass grafts were patent. Signs of pulmonary embolism were not found. Atherosclerosis of the ascending aorta was of minor degree. Histologic examination showed no inflammation or cystic medial necrosis (Figure 1, B).

\section{Comment}

CABG is a widely applied and relatively safe procedure to treat coronary arterial disease, with a general mortality rate of $1 \%$ to $3 \%$. Clinicians are aware of the complications usual after the procedure, such as venous graft occlusion, myocardial infarction, and congestive heart failure. Stanford type A aortic dissection is among the more unusual complications of cardiac surgery with cardiopulmonary bypass, with frequencies ranging from $0.12 \%$ to $0.35 \% .{ }^{1-3}$ Most cases are detected during the operation or in the immediate postoperative period. Then the intimal tear most commonly arises from the aortic cannulation site or site of aortic crossclamping. ${ }^{1-3}$ If aortic dissection occurs within the first postoperative month, the intimal tear is preferentially located next to or continuous with the venous graft insertion site, as illustrated in this case. ${ }^{1,3,4}$ Long-standing arterial hypertension, postoperative hypertensive episodes, severe atherosclerosis, aortitis, and cystic medial necrosis all seem to promote aortic dissection. ${ }^{1-4}$ Generally, dissection of the ascending aorta is associated with considerable mortality, and surgical repair is further complicated by postoperative conditions.

This report illustrates that aortic dissection, although uncommon, is a further serious consequence of CABG procedures to be taken into account within the first postoperative weeks, especially because symptoms can be mistaken for myocardial infarction. Rapid diagnosis by transesophageal echocardiography or computed tomography and immediate operative repair are necessary. Strict control of postoperative blood pressure as a preventive measure is mandatory. 


\section{References}

1. Murphy DA, Craver JM, Jones EL, Bone DK, Guyton RA, Hatcher CR Jr. Recognition and management of ascending aortic dissection complicating cardiac surgical operations. J Thorac Cardiovasc Surg. 1983;85:247-56.

2. Still RJ, Hilgenberg AD, Atkins CW, Daggett WM, Buckley MJ. In-

traoperative aortic dissection. Ann Thorac Surg. 1992;53:374-9.

3. Ruchat P, Hurni M, Stumpe F, Fischer AP, von Segesser LK Acute ascending aortic dissection complicating open heart surgery: cerebral perfusion defines outcome. Eur J Cardiothorac Surg. 1998;14:449-52.

4. Nicholson WJ, Crawley IS, Logue RB, Dorney ER, Cobbs BW, Hatcher CR Jr. Aortic root dissection complicating coronary bypass surgery. Am J Cardiol. 1978;41:103-7. 